\title{
Una estrategia de desarrollo para la Amazonía fronteriza del norte del Perú
}

\author{
Eduardo Martinetti*
}

\section{RESUMEN}

En el contexto de la próxima celebración del vigésimo aniversario de los Acuerdos de Paz peruano-ecuatorianos de 1998, el artículo examina la ejecutoria del Plan Binacional de Desarrollo de la Región Fronteriza en relación al cumplimiento de su programa original de inversiones destinado a revertir las condiciones de subdesarrollo y elevar la calidad de vida de la población fronteriza. Si bien el nivel del financiamiento público realizado en las últimas dos décadas ha sido sustantivo, el balance general apunta a señalar la persistencia de importantes brechas sociales, económicas y de infraestructura social y productiva en el ámbito amazónico peruano de la zona fronteriza, habitado mayoritariamente por pueblos indígenas.

A partir de dicha constatación, el Capítulo Perú del Plan Binacional se ha planteado retomar las capacidades institucionales previstas en su mandato, así como otras recientemente establecidas por la normativa peruana, a fin de redimensionar su función promotora del desarrollo y articuladora de la gestión gubernamental en el ámbito fronterizo. Al efecto, ha formulado y financiado una estrategia integrada de intervención, que se focaliza en cinco cuencas hidrográficas amazónicas, a partir de la cual viene gestionando la priorización de inversiones públicas en infraestructura social y productiva y el mejoramiento de la prestación de servicios sociales, bajo enfoques de interculturalidad y sostenibilidad.

A fin de escapar al modelo asistencialista, la estrategia propone el desarrollo de capacidades y la transformación paulatina de la base productiva, de manera amigable con el medio natural, como alternativa para lograr el desarrollo social sostenible de las poblaciones amazónicas fronterizas.

Palabras clave: Plan Binacional para el Desarrollo de la Región Fronteriza Perú-Ecuador, Capítulo Perú del Plan Binacional, Fondo Binacional Perú-Ecuador, Acuerdo amplio peruano-ecuatoriano de integración fronteriza, Acuerdos de Paz Perú-Ecuador, Zona de integración fronteriza Perú-Ecuador

\footnotetext{
* Director ejecutivo del Capítulo Perú del Plan Binacional de Desarrollo de la Región Fronteriza Perú-Ecuador, Lima-Perú. Embajador en el Servicio Diplomático del Perú. Correo electrónico: emartinetti@planbinacional.org.pe
} 


\section{A Development Strategy for the Northern Amazonian Border of Peru}

\section{Abstract}

In the context of the upcoming celebration of the twentieth anniversary of the PeruvianEcuadorian Peace Agreements of 1998, the article examines the performance of the Binational Plan for the Development of the Peru-Ecuador Border Region (Plan Binacional para el Desarrollo de la Región Fronteriza Perú-Ecuador) in compliance with its original investment program aimed at reversing underdevelopment conditions and raising the quality of life of the border population. Although the public financing made in the last two decades has been substantial, an overall assessment points to the persistence of important social, economic as well as social and productive infrastructure gaps within the Amazonian area of the Peruvian border, inhabited mainly by indigenous peoples.

Based on this verification, the Peruvian Chapter of the Binational Plan (Capítulo Perú del Plan Binacional) has set out to restore institutional capacities envisaged in its mandate, as well as others recently established by Peruvian legislation, in order to strengthen its development-promoting and government management-articulation functions in the border area. To this end, it has drawn and is financing an integrated intervention strategy focused on five Amazonian river basins, while promoting at the same time the prioritization of public investments in social and productive infrastructure as well as the improvement of social services provided in the area, under interculturality and sustainability approaches.

In order to overcome the welfare approach, the strategy proposes the development of skills and the gradual transformation of the productive base, in a friendly way with the natural environment, as an alternative to achieve the sustainable social development of the Amazonian border populations.

Keywords: Binational Plan of Development of the Peru-Ecuador Border Region, Peruvian Chapter of the Binational Plan, Peruvian-Ecuadorian Peace Agreements, Binational Fund Peru-Ecuador, Comprehensive Peruvian-Ecuadorian Border Integration Agreement, Border Integration Zone Peru-Ecuador

\section{Introducción}

Con el objeto de hacer un balance de la primera década de los Acuerdos de Paz de 1998, Fabián Novak y Sandra Namihas realizaron una extensa y documentada investigación que fue publicada en la Serie de Política Exterior Peruana de esta revista del Instituto de Estudios Internacionales (IDEI), bajo el título «Perú-Ecuador: una experiencia exitosa de paz y buena vecindad» (2010).

Se trata de un extenso y brillante artículo de consulta obligatoria, que sintetiza la histórica relación bilateral peruano-ecuatoriana, plagada de desacuerdos, incidentes y conflictos de índole fronteriza que precedieron a la denominada Guerra de El Cenepa y a las negociaciones de paz de 1998. Al efecto, recogieron testimonios valiosos de 
importantes actores de ambas nacionalidades y de los cuatro Países Garantes que participaron en el proceso, describiendo una serie de factores que hicieron posible alcanzar los Acuerdos de Paz.

Además, y como conclusión, Novak y Namihas (2010) reflejaron que,

[...] en casi toda su historia republicana, Perú y Ecuador tuvieron en su frontera un punto de desencuentro y conflicto, y no de cooperación y desarrollo común. La escasa o nula inversión de los Estados y de los agentes privados en las zonas fronterizas se explicaba por la falta de seguridad y los constantes enfrentamientos entre ambos países, lo que se tradujo en un mayor empobrecimiento y abandono de las poblaciones allí existentes (p. 14).

Sin embargo, al evaluar los once años siguientes, el citado artículo reconoció y mostró evidencia de los extraordinarios logros alcanzados en todo orden de cosas, partiendo de la calidad del entendimiento y del relacionamiento político bilateral que hizo posible concretar sustantivos avances en materia de seguridad, intercambio comercial, promoción de inversiones recíprocas, turismo, desarrollo e integración fronterizos, entre otros.

Reviste interés particular para el presente artículo destacar el detallado capítulo dedicado por Novak y Namihas a la ejecución de proyectos de desarrollo económico y social en el ámbito fronterizo binacional (2010, pp. 40-58). La significativa inversión en materia de infraestructura social y productiva realizada por ambos países en el marco del Plan Binacional ha permitido que un amplio sector de la población fronteriza de ambos países empiece a usufructuar los beneficios tangibles de la paz alcanzada en 1998.

No obstante ello, para los pobladores del ámbito rural de la sierra norte y, particularmente para las decenas de miles de indígenas y colonos que habitan el inmenso territorio amazónico peruano fronterizo con el Ecuador (sobre la margen izquierda del Marañón-Amazonas), subsisten aún hoy condiciones de vida y privación de derechos fundamentales que contrastan marcadamente con las que gozan las poblaciones de la costa peruana e incluso con las que se dan en las urbes y capitales regionales a las que dichos territorios pertenecen.

Como se verá más adelante, en las casi dos décadas transcurridas desde los Acuerdos de Paz el Estado peruano realizó una cuantiosa inversión en infraestructura física y para la dotación de servicios básicos en la región fronteriza que, lamentablemente, se contrastan con la subsistencia de brechas sociales enormes, que crecen a medida que nos alejamos de la costa en dirección al nororiente. Pero, además, la institucionalidad del Estado se enralece también hasta casi desaparecer a medida que transitamos en esa dirección. Para la población de los vastos territorios nororientales del Perú pocas 
cosas han cambiado para bien a pesar del importante esfuerzo realizado y es menester preguntarse por qué.

El presente artículo se centra en los desafíos que debe asumir el Capítulo Perú del Plan Binacional, en la responsabilidad que la Nación y el Estado peruanos tienen históricamente pendiente en la zona amazónica de la frontera norte y en las amenazas de diversa índole que se ciernen sobre ella. Es propósito del artículo contribuir a poner estos temas en el centro del debate nacional y comenzar a desplegar estrategias para una planificación integral e integrada de la acción sectorial e intergubernamental para el desarrollo. A estos efectos, el Capítulo Perú del Plan Binacional invita a considerar un modelo de intervención focalizado en cuencas hidrográficas, que busca generar impactos sostenibles y verificables de desarrollo a partir de su Programa de Inversión Inter Cuencas Amazónicas (PIICA-I), que requiere ser a su vez articulado con las inversiones del Estado y concitar la participación de la sociedad civil.

\section{El Plan Binacional y la inversión en infraestructura social y productiva en la frontera norte (2000-2017)}

\subsection{Vigencia del acuerdo amplio}

Conforme al Acuerdo Amplio Peruano Ecuatoriano de Integración Fronteriza, Desarrollo y Vecindad, suscrito en el marco de los Acuerdos de Paz peruano-ecuatorianos de 1998, el Plan Binacional de Desarrollo de la Región Fronteriza fue creado con el mandato de contribuir a elevar el nivel de vida de las poblaciones que habitan dicho ámbito e impulsar la integración y la cooperación entre los dos países, a través de actividades, proyectos y programas que aceleren su desarrollo productivo y social, procurando minimizar los efectos negativos de impacto ambiental. Para el efecto el Plan Binacional fue conformado por cuatro "Programas» de desarrollo y, operativamente, fue dotado de un Capítulo Perú y un Capítulo Ecuador, responsables de articular de manera conjunta las inversiones del Programa de Proyectos Binacionales (Programa «A», para la integración y cooperación transfronteriza). Cada uno de los Capítulos asumiría, de manera independiente, la coordinación de los Proyectos Nacionales de Infraestructura Productiva (Programa «B») y Social (Programa "C») que sus respectivos gobiernos debieran impulsar en el ámbito de la región fronteriza. El cuarto Programa («D», para la inversión privada) constituyó una invitación a identificar proyectos de inversión de impacto regional que pudieran ser ejecutados y financiados por los sectores empresariales de ambos países.

Se establecieron también cuatro diferentes mecanismos de financiamiento en apoyo a la ejecución de los citados Programas. De ellos solamente el Fondo Binacional para la Paz y el Desarrollo se ha mantenido en el tiempo, aunque con algunos cambios 
respecto a su institucionalidad original. El Fondo, como brazo financiero del Plan, ha invertido correctamente los recursos anuales entregados por el tesoro, así como aquellos que le fueron confiados por las agencias de cooperación internacional.

La auspiciosa expectativa inicial de captar tres mil millones de dólares para inversiones en toda la región fronteriza sufrió un proceso de rápido sinceramiento en el lado peruano debido a que ese financiamiento no se hizo inmediatamente disponible y debido también a importantes condicionamientos propios de la realidad peruana. Entre los más importantes, el muy significativo retraso histórico en la inversión para el desarrollo de la región fronteriza, que puso de manifiesto la dificultad para cerrar las grandes brechas sociales y productivas en la zona; agravada por la carencia de políticas, planes estratégicos y proyectos integrados para atenderla debidamente; y, no menos importante, por la falta de sincronía en el diseño y ejecución de los programas sectoriales, que ha restado impacto, sinergias y sostenibilidad a la inversion que ha venido realizando el Estado en los últimos veinte años.

No obstante, continua vigente la esencia del Acuerdo Amplio, así como el mandato del Plan Binacional para enfrentar la pobreza y la marginación de las poblaciones vulnerables de la zona de frontera, cerrar las principales brechas productivas y de infraestructura de conectividad, electrificación y saneamiento, así como para fortalecer la integración y la cooperación binacional que se require para facilitar los procesos económicos y sociales transfronterizos, particularmente del nororiente peruano con el ámbito ecuatoriano correspondiente. Para ello será esencial que el Plan Binacional actúe y sea crecientemente reconocido como un mecanismo convocante, articulador y promotor del desarrollo en la región fronteriza.

\subsection{El modelo y los resultados}

A diferencia del Ecuador, que estableció el Programa Regional para el Desarrollo del Sur (Predesur), en la década de 1990, el Perú eliminó a partir de esa misma década la planificación estratégica para el desarrollo ${ }^{1}$, sustituyéndola por las dinámicas propias del mercado. Sin planes de desarrollo nacionales, regionales y locales, sin información confiable respecto a la vasta y heterogénea región fronteriza, secularmente olvidada y con grandes asimetrías de desarrollo respecto al territorio ecuatoriano vecino, el Estado peruano y el Capítulo Perú del Plan Binacional se encontraron casi a ciegas para organizar su intervención en la zona.

\footnotetext{
1 El Instituto Nacional de Planificación (INP) fue disuelto en el año 1992 mediante Decreto Ley 25548, siendo sus funciones asumidas por el Ministerio Economía y Finanzas con excepción de las de cooperación internacional.
} 
Una notable excepción ha estado constituida, sin embargo, por la ejecución de varios de los Proyectos Binacionales de infraestructura (Programa «A»), como es el caso de la prioridad otorgada por los sucesivos gobiernos de ambos países a la construcción y/o rehabilitación de cuatro ejes viales que hoy vinculan a porciones importantes del territorio fronterizo peruano-ecuatoriano, integrando crecientemente a sus poblaciones y economías.

En cuanto al Plan Binacional, fue oportuna la temprana convocatoria del Capítulo Perú a los Foros Departamentales, que tuvieron una amplia participación de organizaciones públicas y privadas y de los cuales lamentablemente solo se realizaron dos de los cinco originalmente proyectados (en Tumbes y Amazonas); así como la estructuración multisectorial de los Programas de Inversión en Infraestructura Básica (PIIB), concertados con los alcaldes provinciales de los departamentos de Tumbes, Piura, Cajamarca y Amazonas, que permitieron en los años subsiguientes estructurar una amplia colaboración del Plan Binacional con los Ministerios de Transportes y Comunicaciones (MTC), Energía y Minas (MEM) y Vivienda, Construcción y Saneamiento (MVCS) para la construcción de caminos a las capitales distritales, electrificación rural e interconexiones eléctricas transfronterizas y, con limitaciones, inversiones en agua y saneamiento. Dificultades de diversa índole en Loreto impidieron definir opciones de intervención en ese departamento.

La mayor parte de la importante contribución de los países amigos (cooperación no reembolsable) fue recibida y ejecutada en los primeros diez años, alcanzando un total de 192,68 millones de dólares para el financiamiento de proyectos propiamente binacionales. En sentido contrario a la idea inicial, consignada en el Acuerdo Amplio, de que el Fondo Binacional administraría todos los recursos financieros del Plan, la mayor parte de las fuentes de cooperación no reembolsable (CNR) plantearon sus propias líneas de intervención y optaron por administrar sus propios recursos. Asi, la tarea del Fondo se orientó, con pocas excepciones, al registro de los aportes de la CNR y a formular propuestas para «apalancar» nuevos recursos.

No obstante, la dificultad para continuar captando recursos de la CNR se puso de manifiesto muy rápidamente. Suscritos los acuerdos de paz, el ámbito territorial dejó de ser prioritario, surgieron nuevas demandas en otras partes del mundo y la cooperación internacional comenzó a redireccionar sus aportes.

Ante la falta de apropiaciones adecuadas por parte del Estado y a la lentitud y direccionamiento con que llegaba la CNR, en el año 2003 se hizo evidente la brecha de financiamiento para acometer la gran tarea prevista en el Acuerdo Amplio. En este contexto, los presidentes del Perú y el Ecuador decidieron designar a sendos Comisionados Nacionales para que formularan recomendaciones para el «relanzamiento del Plan Binacional». 
Entre tanto, el Capítulo Perú encargó realizar un diagnóstico (Giesecke, Lafosse y Purizaca, 2003) que resultó sumamente revelador. Este informe confirmó, entre otros puntos, la extraordinaria magnitud del esfuerzo realizado en los primeros ańos para gestar y ejecutar una cartera muy amplia de proyectos, particularmente referidos a los Programas «A» $\mathrm{y}$ «C » del Acuerdo Amplio.

Las importantes inversiones en infraestructura física verificadas por el diagnóstico del 2003 y, mas adelante, por la investigación de Novak y Namihas (2010), continuaron verificándose en líneas generales de manera sostenida hasta el año 2016, en que concluyó la ejecución de destacadas obras como el Eje Vial 4 y otras de electrificación rural y vialidad para las capitales distritales de la costa y sierra peruanas.

La magnitud del financiamiento (de diversas fuentes) realizado al 2016, en el marco del Plan Binacional, se pone de manifiesto en el siguiente cuadro que muestra que se han duplicado los estimados de inversión para la región fronteriza peruana que se hicieron al momento de la firma de la paz.

El cuadro 1 muestra que los 3667,10 millones de dólares de inversión concretados hasta el 2016 fueron aportados principalmente por el tesoro público, la cooperación internacional no reembolsable (CNR) y por inversiones privadas en el ámbito de las concesiones. Asimismo, muestra que las obras de infraestructura física constituyeron la mayor parcela de las inversiones (2922,17 millones de dólares), siendo destinadas a obras de transporte y comunicaciones, desarrollo urbano, agua y saneamiento, electrificación y a proyectos multisectoriales. Todos los programas sectoriales, excepto Desarrollo Urbano, recibieron recursos de CNR, que para el periodo representan el $3,5 \%$ del total (sin considerar las concesiones).

Cuadro 1. Principales inversiones por sectores a 2016 (en millones de dólares)

\begin{tabular}{lcccc}
\hline Sectores & $\begin{array}{c}\text { Cooperación no } \\
\text { reembolsable }\end{array}$ & $\begin{array}{c}\text { Recursos } \\
\text { nacionales }\end{array}$ & $\begin{array}{c}\text { Conce- } \\
\text { siones }\end{array}$ & Total \\
\hline Agua y Saneamiento & 24,45 & 728,47 & & 752,92 \\
Electrificación & 1,86 & 212,74 & & 214,60 \\
Desarrollo Urbano & & 166,33 & & 166,33 \\
Transporte y Comunicaciones & 42,64 & 862,42 & 865,26 & 1770,32 \\
Multisectorial & 3,06 & 14,93 & & 18,00 \\
\hline Total Infraestructura Física & 72,01 & 1984,89 & 865,26 & 2922,17 \\
\hline Educación y Salud & 23,30 & 51,67 & 0,00 & 74,97 \\
Medio Ambiente y Agricultura & 67,62 & 56,92 & 0,00 & 124,54 \\
Multisectorial y otros & 29,75 & 15,68 & 500,00 & 545,43 \\
\hline Total & 192,68 & $\mathbf{2 1 0 9 , 1 6}$ & $\mathbf{1 3 6 5 , 2 6}$ & 3667,10 \\
\hline
\end{tabular}

Fuente: Plan Binacional de Desarrollo de la Región Fronteriza Perú-Ecuador, 2017. 
Las comprobaciones realizadas, siendo importantes, no resuelven no obstante las limitaciones que quedan planteadas al momento de evaluar con mayor rigor la ejecutoria gubernamental y del Plan Binacional con relación al desarrollo económico y social de este ámbito fronterizo peruano.

A lo largo de todo el período, hasta 2017, el Plan Binacional ha contribuido a la realización de las grandes obras de infraestructura física ejecutada por los sectores gubernamentales, «apalancando» recursos del propio Estado, financiado estudios de preinversión (viales, de electrificación y de saneamiento, entre otros) e incluso cofinanciando la construcción de algunos puentes de los Ejes Viales 1 y 4 . No obstante ello, un hallazgo destacado del diagnóstico del año 2003 revelaba ya que, a pesar de los niveles de colaboración alcanzados con varios sectores gubernamentales, no se había llegado a plasmar un acuerdo político con el Gobierno que permitiera al Plan Binacional convertirse en su gran operador para el desarrollo de la zona fronteriza.

Más adelante haremos referencia específica a las conclusiones del Comisionado Nacional peruano con relación al «relanzamiento del Plan». Por el momento baste señalar que no se alcanzaron a implementar la mayor parte de las recomendaciones allí planteadas con la finalidad de dar aliento a la tarea de transformación económica y social de la zona fronteriza. Al margen del aporte anual, que a partir de los ańos 2004 y 2005 ha venido entregando el Estado al Fondo Binacional para el financiamiento de pequeños y medianos proyectos, el Plan Binacional — como tal- no consiguió comprometer recursos nacionales suficientes para acometer la gran responsabilidad que le fuera encomendada en el Acuerdo Amplio, actuando en gran medida por demanda de los gobiernos locales y de las organizaciones sociales de base para la ejecución de pequeños y medianos proyectos.

Esto no quiere decir que el Fondo Binacional, administrado desde la Dirección Ejecutiva Nacional del Plan Binacional, no haya cumplido con su responsabilidad estatutaria de apoyar y cofinanciar los pequeños y medianos proyectos que en gran número han resuelto necesidades vitales de las poblaciones y comunidades más pobres y vulnerables del ámbito fronterizo. Todo lo contrario, la ejecutoria del Fondo Binacional, que queda revelada en los cuadros siguientes, constituye una constatación de la admirable gestión realizada, con un muy alto grado de eficiencia en la gestión de las 658 obras financiadas y cofinanciadas con gobiernos locales y organizaciones sociales de base. El Fondo se ha caracterizado por su confiabilidad en cuanto a la naturaleza, calidad y oportunidad de las obras que ha financiado, así como por la eficaz supervisión realizada sobre los ejecutores directos. En esa medida, es importante destacar la tarea cumplida por el Fondo, que le ha redituado al Plan Binacional gran parte de la legitimidad que ostenta entre los pueblos y las instituciones de los distritos más apartados de la zona fronteriza. 
Cuadro 2. Proyectos y estudios cofinanciados por el Fondo Binacional Por sector, 2000-2017

\begin{tabular}{lcrrrrr}
\hline Sector & $\begin{array}{c}\mathbf{N}^{\circ} \\
\text { Proyectos/ } \\
\text { estudios }\end{array}$ & $\begin{array}{c}\text { Fondo } \\
\text { Binacional }\end{array}$ & \multicolumn{1}{c}{ Otros } & \multicolumn{1}{c}{ Total } & $\begin{array}{c}\text { Población } \\
\text { beneficiaria } \\
\text { aprox. }\end{array}$ & $\begin{array}{c}\text { \% Distrib. } \\
\text { de } \\
\text { inversión }\end{array}$ \\
\hline Agricultura & 70 & 3946282 & 4827885 & 8774167 & 10016 & 0,7 \\
Ambiente & 5 & 190127 & 224626 & 414753 & 28938 & 1,9 \\
Cultura & 2 & 28049 & & 28049 & 199000 & 13,1 \\
Educación & 220 & 11386390 & 6596435 & 17982825 & 14500 & 1,0 \\
Energía & 52 & 2104582 & 4325746 & 6430328 & 4949 & 0,3 \\
Industria & 15 & 161636 & 235948 & 397584 & 5150 & 0,3 \\
Multisectorial & 23 & 1092900 & 802949 & 1895849 & 77884 & 5,1 \\
Produce & 7 & 675084 & 1462455 & 2137538 & 6480 & 0,4 \\
Salud & 94 & 5260120 & 4741331 & 10001451 & 594031 & 39,0 \\
Aguay Saneamiento & 94 & 3163432 & 6211085 & 9374517 & 3398 & 0,2 \\
Social & 11 & 530102 & 353209 & 883311 & 423941 & 27,8 \\
Transp. y Comunic. & 55 & 3681935 & 21407836 & 25089771 & 64169 & 4,2 \\
Turismo & 8 & 141216 & 40038 & 181254 & 7140 & 0,5 \\
Vivienda & 2 & 296597 & 3207640 & 3504237 & 82827 & 5,4 \\
\hline \multicolumn{1}{c}{ TOTALES } & 658 & $\mathbf{3 2 6 5 8 4 5 1}$ & 54437182 & 87095633 & 1522423 & $\mathbf{1 0 0}$ \\
\hline
\end{tabular}

Fuente: Fondo Binacional, 2017.

Cuadro 3. Proyectos y estudios cofinanciados por el Fondo Binacional Por departamento, 2000-2017

\begin{tabular}{lcrrrrr}
\hline \multirow{2}{*}{ Departamento } & $\begin{array}{c}\mathrm{N}^{\circ} \\
\text { Proyectos/ } \\
\text { estudios }\end{array}$ & $\begin{array}{c}\text { Fondo } \\
\text { Binacional }\end{array}$ & \multicolumn{1}{c}{ Otros } & Total & $\begin{array}{c}\text { Población } \\
\text { beneficiaria } \\
\text { aprox. }\end{array}$ & $\begin{array}{c}\text { \% Distrib. } \\
\text { de } \\
\text { inversión }\end{array}$ \\
\hline Amazonas & 151 & 7948358 & 11980375 & 19928733 & 147293 & 10 \\
Cajamarca & 146 & 6939244 & 8860079 & 15799323 & 500219 & 33 \\
Loreto & 59 & 2244247 & 5820297 & 8064544 & 92783 & 6 \\
Piura & 208 & 10952324 & 19493589 & 30445913 & 415754 & 27 \\
Tumbes & 70 & 3735211 & 7402352 & 11137562 & 272345 & 18 \\
Multidepartamental & 24 & 839068 & 880490 & 1719558 & 94029 & 6 \\
\hline TOTALES & $\mathbf{6 5 8}$ & $\mathbf{3 2 6 5 8 4 5 1}$ & 54437182 & $\mathbf{8 7 0 9 5 6 3 3}$ & $\mathbf{1 5 2 2 4 2 3}$ & $\mathbf{1 0 0}$ \\
\hline
\end{tabular}

Fuente: Fondo Binacional, 2017. 


\section{Situación socioeconómica de la población peruana en la Amazonía norte}

En un interesante documento de Luis Oliveros se describe algunas características de la región fronteriza peruano-ecuatoriana al momento de suscribirse los Acuerdos de Paz. Según Oliveros:

[...] en síntesis, las inversiones en infraestructura social y productiva efectuadas por el Estado ecuatoriano a través del organismo específicamente creado para promover el desarrollo del sur del Ecuador (Predesur), utilizando parte de los recursos generados desde la década de 1970 por el auge de la explotación petrolera, han sentado una significativa diferencia en infraestructura y equipamiento básico entre los sectores peruano y ecuatoriano de esta zona andino-occidental de la frontera, como consecuencia de lo cual la parte ecuatoriana tiene un nivel de desarrollo y de cohesión, a nivel regional y nacional, mucho mayor del que ofrece la zona equivalente en territorio peruano. [...] ningún área humanizada del país (Ecuador) se halla demasiado alejada como para no beneficiarse de una cada vez más acentuada cohesión espacial y de los efectos del crecimiento económico (1998).

En contraste, en el Perú la presencia del Estado y de los distintos actores que podrían impulsar el desarrollo de su región fronteriza ha sido significativamente menor, tanto por razones geográficas, ecológicas y económicas, así como por las orientaciones de las políticas públicas y las prácticas de los sectores y de la administración pública. Cinco años después de los Acuerdos de Paz, la antes citada consultoría encargada por el Capítulo Perú revelaba que «en la parte peruana de la región fronteriza con el Ecuador, con la excepción de Tumbes y Piura, la mayor parte de hogares (entre el 80 y $100 \%$ ) no tiene alumbrado eléctrico, el $80 \%$ tiene necesidades básicas insatisfechas. La vialidad es escasa y deficitaria [...] [y] los retos que tiene el Plan Binacional son amplísimos en cuanto al desarrollo fronterizo y a la integración. Está casi todo por hacer». El citado informe concluye que, en consecuencia "la estrategia para captar recursos no puede estar desligada de las definiciones sobre los quehaceres del Plan [...]. El panorama es pues que el cumplimiento de las tareas del Plan y su financiamiento serán materia de arduas negociaciones con los sectores y con las fuentes de Cooperación no Reembolsable (Giesecke, Lafosse y Purizaca, 2003).

Un lustro después, Drago Kisic encontró que «en el caso del Perú [...] ha habido una disminución de la pobreza en las zonas fronterizas, especialmente en la región Tumbes. No obstante, la pobreza sigue estando por encima de la media nacional en Piura, Amazonas y Cajamarca (2008, p. 9).

\subsection{Brechas sociales}

Al examinar y comparar el nivel de las brechas sociales y de infraestructura prevalecientes hasta el momento en las diferentes regiones del ámbito fronterizo norperuano 
podemos reconocer, en términos relativos y absolutos, la grave situación de pobreza, desvinculación y postergación que se vive en el espacio amazónico y, particularmente, en los distritos de población indígena mayoritaria.

Los actuales indicadores sociales son extremadamente preocupantes, en particular los refereidos a cuencas amazónicas como la del Cenepa, cuya población registra una pobreza monetaria de $92 \%$ y una pobreza extrema de $32,7 \%$, así como un índice de anemia de 56\%, que se ven agravados por la desarticulación de la mayor parte de la cuenca con el resto de la región por la carencia de vías de comunicación que impiden un desarrollo productivo más dinámico y la posibilidad de transportar sus excedentes a los mercados locales.

Como se aprecia en el cuadro 4, los distritos de las provincias de Bagua y Condorcanqui (en la región Amazonas), así como el distrito vecino del Morona (en Loreto), muestran brechas cercanas a las de El Cenepa, tanto en desnutrición infantil como en servicios básicos (agua segura y electricidad). La información de base examinada revela que estas brechas, en conjunto, duplican las de la región Amazonas y triplican la media nacional.

En esta medida, el diagnóstico institucional emprendido por el Capítulo Perú, a partir de abril de 2017, mostró rápidamente la necesidad de trazar lineamientos estratégicos que permitieran mejorar el impacto de las intervenciones futuras del Plan.

\subsection{Tránsito cultural de la población indígena amazónica}

Aún cuando no es objeto del presente artículo y, a riesgo de caer en inconvenientes generalizaciónes, no es posible sustraerse a realizar una suscinta referencia a la población indígena amazónica y a los condicionantes o restricciones que prevalecen hoy para su desarrollo en la zona nor oriental de la frontera peruana.

La Amazonía peruana alberga trece familias lingüísticas y 42 grupos étnicos distribuidos en sus diferentes regiones, de los cuales 21 se encuentran en la región fronteriza peruano-ecuatoriana y seis tienen características transfronterizas.

En un escenario de crecimiento poblacional y de insatisfacción de necesidades, en los últimos años se intensificó la presión de las comunidades indígenas sobre los recursos naturales. Ello está obligándolas a disminuir su dependencia de actividades tradicionales de subsistencia, como la caza y la pesca, y a incrementar paulatinamente las áreas bajo producción agrícola, en particular con el cultivo de productos de mayor aceptación en el mercado, con el propósito fundamental de generar ingresos monetarios que viabilicen su acceso complementario a servicios de salud y educación, así como a bienes que no son producidos localmente. 


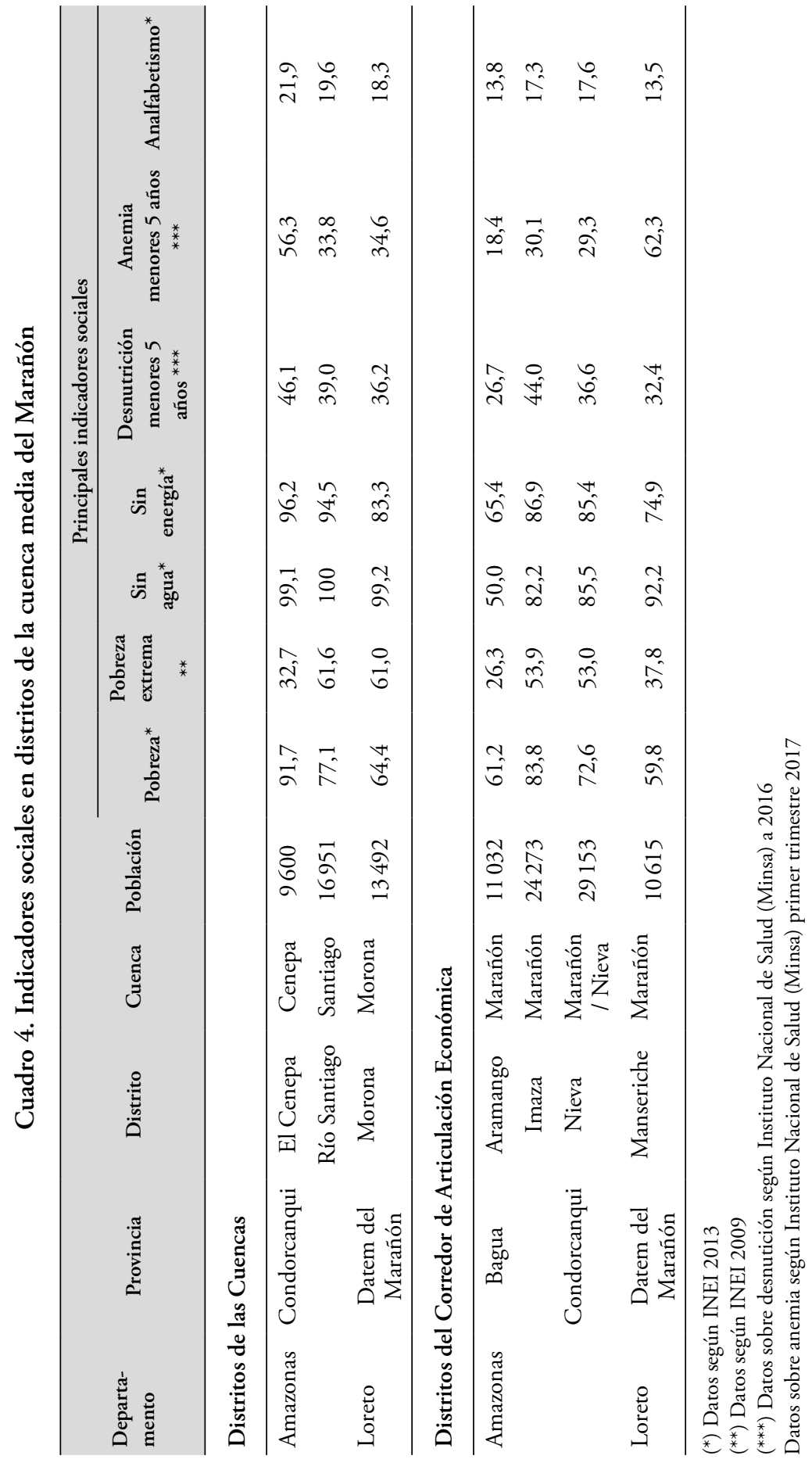


En 2012, el Capítulo Perú encargó la realización de un estudio sobre los aspectos más importantes de la problemática de las poblaciones originarias amazónicas que habitan en el entorno fronterizo norte. El estudio, al que haremos extensa referencia, abre una serie de perspectivas para situar lo que aquí denominaremos como "tránsito cultural»; que comienza por reconocer «la naturaleza marginal con la que el Perú precolombino, colonial y republicano ha mirado a sus poblaciones indígenas amazónicas, al punto que recién en 1974, de manera oficial, el gobierno reconoció su existencia formal y los derechos que como peruanos les corresponden» (Druschke, Alvarado Jesús, Pajares, Mora y Curo, 2012).

$\mathrm{Al}$ apuntar a la «brecha radical y profunda que separa a la sociedad mayor peruana de las sociedades indígenas amazónicas —en razón a las grandes distancias físicas, conceptuales e históricas entre ambas - la primera no percibe que las segundas se encuentran actualmente en un proceso difícil —algunos dirán «doloroso»— de transición entre sus tradiciones y el entorno moderno del país, cada vez más fluido y dinámico» (Druschke et al., 2012). Aún cuando en su largo devenir las poblaciones originarias se organizaron tradicionalmente en torno a nucleos familiares $y$, eventualmente en torno a comunidades de la misma raíz étnica, recientemente han forjado numerosas federaciones indígenas que han asumido como objetivo la defensa de sus territorios, la revaloración de su cultura y la representación de sus disgregadas comunidades ante el Estado. Varias de estas federaciones se oponen a las actividades de empresas extractivas asumiendo que contaminan el medio ambiente y no generan mejoras en las condiciones de vida de sus comunidades.

En suma, «la población indígena se encuentra atrapada entre dos discursos: el que surge de su propia condición marginal — de la que quiere liberarse (promoviendo) el éxito de sus hijos-y aquel (otro) generado por las dirigencias y sus asesores políticos externos, el discurso y la acción de los agentes pastorales y los representantes de ONG que aluden directamente a las heridas aún abiertas que perturban sus vidas, a la necesidad de enfrentarse a los causantes de esa situación, el Estado y las empresas (Druschke et al., 2012).

En esta dinámica, una serie de dirigencias han ido construyendo propuestas para conformar gobiernos autonómicos indígenas, que reivindican su autodeterminación territorial y administrativa. Asimismo, «desde el Ecuador [...] se han dado las iniciativas más intensas de "integración» binacional en materia de pueblos indígenas... por las activas propuestas de desarrollo de encuentros binacionales (y) desde 1998 (para) la conformación de entidades indígenas binacionales y la propuesta de constitución de territorios binacionales indígenas» (Druschke et al., 2012).

No obstante, «hasta la fecha no han existido en el Perú políticas públicas coherentes, articuladas y continuas para los pueblos indígenas y el tema indígena no forma parte 
de la agenda política nacional explícita [...] Es imprescindible acercarse al conocimiento de la problemática indígena amazónica y forjar urgentemente procesos nuevos que conduzcan a una inserción menos [...] traumática de nuestros pueblos originarios a la sociedad mayor peruana» (Druschke et al., 2012).

\subsection{Cobertura de los servicios básicos}

Al surcar los ríos y adentrarse en la vastedad de los territorios de las cuencas y subcuencas de la Amazonía norte sobreviene de inmediato la percepción del dominio del medio natural, condicionante fundamental de la vida de las poblaciones que las habitan. Ello explica la arraigada pervivencia de formas de vida y cosmovisiones que se resisten al cambio, no obstante el contacto que tienen las comunidades y las influencias que reciben a partir de una creciente interacción y conectividad con el mundo exterior. De hecho, la forma más institucionalizada de la presencia de la sociedad mayor es la escuela y, en menor grado, los establecimientos de salud, a los que se suma, de manera creciente, la recepción de señales de radio y televisión. Los municipios distritales, que son el eslabón primario de la institucionalidad del Estado, se esfuerzan por asentar su ascendiente y legitimidad en un contexto de limitadas capacidades de gestión y de presupuestos recortados. En estos ámbitos amazónicos próximos a la frontera norte brillan por su ausencia la mayor parte de las entidades del estado promotoras de desarrollo, así como las llamadas a brindar seguridad y ofrecer garantía de derechos.

La intervención estatal se ve seriamente limitada por las dificultades de acceso, barreras geográficas, culturales y sociales de la población. La falta de conectividad dificulta seriamente la provisión de los programas asistenciales, requiriendo de mayores gastos, no siempre disponibles, para llegar hasta la población objetivo y explica también, de alguna manera, las deficiencias que se constatan en la calidad y alcance de los servicios de educación, salud, de infraestructura y logística que reflejan una presencia poco efectiva de la institucionalidad pública.

Los servicios de educación y salud, así como los proyectos de agua y saneamiento, electrificación rural y comunicaciones que impulsan los sectores gubernamentales no están cerrando las brechas con la efectividad y celeridad requerida. En muchos casos los proyectos sectoriales no han registrado el impacto deseado ni han alcanzado sostenibilidad al no comprender la naturaleza y complejidad del ámbito social y natural en el que se interviene.

Los programas sociales, que en las últimas décadas han ido extendiendo su cobertura hacia las regiones más apartadas de la Amazonía, ofrecen un alivio tópico a la situación de extrema pobreza que, como hemos visto, afecta a sectores importantes 
de la población indígena amazónica. Cabe advertir que, aun cuando necesarias, por lo general las formas de asistencialismo no llegan a generar impactos duraderos en las condiciones de vida de la gente, no desarrollan capacidades y no son sostenibles en sí mismas. Vulneran en última instancia la autoestima, generando dependencia.

La muy pobre o inexistente presencia de la institucionalidad estatal, llamada a brindar garantías y seguridad tanto a la población indígena como a la mestiza, provocan ya de manera visible expresiones políticas de rechazo y animadversion que se expresan con cada vez mayor frecuencia en movilizaciones que denotan conflictividades no resueltas.

Más aún, la amplia brecha en infraestructura física y de servicios, las condiciones de exclusión, la escasa preparación de los jóvenes, la falta de oportunidades de trabajo y la débil presencia del Estado son el fermento que propicia la aparición y arraigo de diversas actividades ilícitas vinculadas a la droga, la tala y la minería ilegal.

\section{Hacia una estrategia integral de intervención}

\subsection{Normativa sobre desarrollo e integración fronteriza}

A fines de la década de 1980, los países latinoamericanos comenzaron a estructurar tratamientos específicos para atender las necesidades básicas de sus poblaciones y territorios de frontera. En 1987, la Comunidad Andina comprometió a sus estados miembros a emprender «acciones conjuntas en las áreas fronterizas destinadas a impulsar el desarrollo integral de las zonas de frontera y vincular indisolublemente a los países miembros, así como robustecer la unidad geoeconómica entre ellos» ${ }^{2}$.

La vocación integracionista andina se fortaleció con la aprobación de la Decisión 501 que crea las Zonas de Integración Fronteriza (ZIF), para las que se adoptarán "políticas y ejecutarán planes, programas y proyectos para impulsar el desarrollo sostenible y la integración fronteriza de manera conjunta, compartida, coordinada y orientada a obtener beneficios mutuos, en correspondencia a las características de cada uno de ellos» ${ }^{3}$. Como consecuencia, los gobiernos andinos acordaron entre ellos y de manera bilateral el ámbito de sus respectivas ZIF y suscribieron convenios para dotarlos de institucionalidad y fijar sus objetivos de integración fronteriza.

Más aún, a partir de ese momento se hizo evidente la necesidad de los países de innovar sus propios marcos normativos, comenzando por definir sus respectivas políticas nacionales de desarrollo e integración fronterizas. Este proceso despegó en

Artículo 144 del Acuerdo de Cartagena, modificado por el Protocolo de Quito, 1987.

3 Decisión 501 aprobada por el Consejo Andino de Ministros de Relaciones Exteriores el 22 de junio de 2001. 
el Perú en el año 2011, con la aprobación de la Ley Marco para el Desarrollo e Integración Fronteriza (ley 29778) destinada a impulsar el «proceso impostergable de incorporación de las fronteras al patrimonio activo del país», así como dar curso a la integración fronteriza sobre la base del aprovechamiento complementario de las potencialidades y recursos de los ámbitos fronterizos vecinales.

La Ley Marco estableció en su Primera Disposición Complementaria Final que «La Política Nacional de Desarrollo e Integración Fronterizos se armoniza con los acuerdos y mecanismos binacionales y multinacionales de desarrollo e integración fronterizos existentes con los países limítrofes, a propuesta del Ministerio de Relaciones Exteriores». Y, previamente, en su artículo 26, determina que "las secciones nacionales de los mecanismos bilaterales de desarrollo e integración fronterizos forman parte de la institucionalidad para el desarrollo e integración fronterizos del país, a efectos de armonizar la ejecución de esta política». En consecuencia, el Plan Binacional quedó desde entonces formalmente habilitado para participar activamente en la armonización de proyectos y acciones de desarrollo e integración fronterizos que se ejecutan en el ámbito de la región fronteriza Perú-Ecuador. Sin embargo, ello no sucedería de inmediato, en tanto el Plan continuó privilegiando la atención y cofinanciamiento de proyectos por demanda hasta 2017, cuando decidió virar hacia el planeamiento estratégico para una intervención integrada y concertada en el ámbito de la frontera norte ${ }^{4}$.

A partir de abril de 2017 el Capítulo Perú realizó un profundo diagnóstico institucional, teniendo como referencia fundamental el mandato recibido del Acuerdo Amplio de 1998 y las disposiciones normativas antes señaladas. Las recomendaciones emanadas de dicha evaluación encaminaron al Plan a definir lineamientos estratégicos para sus intervenciones futuras (plasmadas en un Plan Operativo Multianual) y, asimismo, a asumir su función articuladora para concertar con los actores y aliados locales una propuesta estratégica de desarrollo e integración de alcance focalizado. Bajo el nuevo enfoque, el Plan promueve la estructuración de programas y proyectos integrales e integrados, que generen impactos reales sobre las condiciones de vida de la población fronteriza, en una perspectiva de sostenibilidad.

\footnotetext{
4 El artículo 58 del Reglamento de la ley marco (D.S. 017-2011-RREE) dispone que «los ámbitos de las secciones nacionales de las Zonas de Integración Fronteriza (ZIF), o sus equivalentes acordadas con los países limítrofes, deben tener sus respectivas estrategias de desarrollo e integración fronteriza para el largo plazo, en concordancia con los intereses nacionales y la Política de Fronteras... Dichas estrategias constituyen el marco para la negociación de planes de desarrollo de la ZIF. Los planes, programas y estrategias de desarrollo [...] se formularán y ejecutarán en forma articulada e integrada, según sea el caso, y concertada entre las entidades públicas responsables, con la participación, en los casos convenidos, de las organizaciones de la sociedad civil.
} 


\subsection{Programa de Inversión Inter Cuencas Amazónicas (PIICA-I). Perspectiva y antecedentes}

La clave para el desarrollo amazónico fronterizo, que es la de promover el manejo sostenible de los ecosistemas para beneficio de la población, fue adecuadamente considerada en el Programa «B» del Acuerdo Amplio de 1998, al priorizar «proyectos integrales orientados al desarrollo de la base productiva", así como "proyectos de infraestructura física productiva que impulsen el desarrollo de la agricultura, agroindustria y turismo, el establecimiento de industrias locales, el mejoramiento del transporte fluvial, aéreo y terrestre, y una buena interconexión vial dentro de cada región ${ }^{5}$.

En esa línea, el Plan Binacional impulsó a partir del 2013 algunos proyectos productivos (cacao, plátano y piscigranjas) en las provincias de Bagua y Condorcanqui (en la región Amazonas). No obstante, el carácter limitado de estos emprendimientos ${ }^{6}$, la respuesta de los diversos actores involucrados y de la población beneficiaria fue enormemente positiva. Los gobiernos locales no solo brindaron cofinanciamiento para los proyectos, en el marco de políticas propias de fomento de capacidades productivas, sino que asumieron el compromiso de darles sostenibilidad y de replicar el modelo de intervención en otros ámbitos de sus circunscripciones. Como resultado de esta alianza, que incluyó a otros actores de la CNR y de las ONG, más de mil familias awajún han venido siendo capacitadas para desarrollar su potencial agrícola y acuícola.

Las evaluaciones expost reflejaron que, a la par de una educación intercultural de calidad para los niños y de una formación técnica para los jóvenes, que hasta el momento no se encuentran disponibles, se torna imperativo priorizar el fortalecimiento de las capacidades productivas de la población amazónica, única forma realista de generar mejores condiciones de vida, generar ingresos familiares y fortalecer la seguridad alimentaria en una perspectiva de sostenibilidad. Para ello será necesario también cerrar las brechas de infraestructura física y logística para el transporte y el comercio.

\section{Necesidad de focalización espacial para generar impacto}

El diagnóstico realizado en el año 2017 partió de la constatación que el desarrollo alcanzado en las diversas regiones de la zona fronteriza norte se caracteriza por ser heterogéneo y desigual. A partir de esa premisa, el Capítulo Perú consideró que el

\footnotetext{
5 Véase el Anexo 5 del Acuerdo Amplio Peruano Ecuatoriano de Integración Fronteriza, Desarrollo y Vecindad, B.2. Proyectos de Desarrollo Sostenible (1998).

6 Los proyectos incidieron en fortalecer capacidades productivas en familias indígenas, pero no en todos los casos alcanzaron a impulsar cadenas de valor o a vincularse a mercados actuales y potenciales.
} 
ámbito territorial de su mandato de intervención ${ }^{7}$ es muy amplio, y que sus recursos son escasos. Por ello, el Plan Operativo Multianual 2017-2019 decidió intervenir en espacios de frontera que presentan mayores niveles de brechas sociales, optando por una intervención focalizada y diferenciada para revertirlas.

El Encuentro Presidencial y la XI Reunión del Gabinete Binacional Perú-Ecuador respaldó esta visión estratégica, comprometiendo al Plan Binacional a «implementar, en coordinación con las instituciones competentes, un modelo de intervención en espacios focalizados de las subcuencas transfronterizas y localidades vecinales a través de proyectos productivos que generen seguridad alimentaria, incremento de ingresos para las familias y facilidades para fortalecer la cadena de valor y el comercio transfronterizos» ${ }^{8}$.

En cumplimiento de esa directiva, el Capítulo Perú reafirmó el enfoque espacial de desarrollo por cuencas hidrográficas, decidiendo intervenir en los territorios definidos por el divorcio de aguas de las cuencas de los ríos Cenepa, Santiago, Nieva y Morona, todas tributarias a la vez de la gran cuenca del Marañón. El diseño tomó en consideración al Eje Vial $\mathrm{N}^{\circ} 4$ como elemento articulador de dichos espacios socioeconómicos, toda vez que corre de modo paralelo a la cuenca del Marañón, constituyendo en la práctica un corredor que articula tres ciudades intermedias de importancia: Chiriaco y Santa María de Nieva en la región Amazonas y Saramiriza en la región Loreto.

Cuadro 5. Población y superficie del área focalizada

\begin{tabular}{lcccc}
\hline \multicolumn{1}{c}{ Distritos } & $\begin{array}{c}\text { Población } \\
\text { proyectada 2017 }\end{array}$ & Superficie $\mathbf{k m}^{2}$ & $\begin{array}{c}\text { Densidad } \\
\left(\text { población/ } \mathbf{k m}^{2}\right)\end{array}$ & $\begin{array}{c}\text { Comunidades reco- } \\
\text { nocidas y tituladas } \\
\left({ }^{*}\right)\end{array}$ \\
\hline El Cenepa & 9600 & 5458,48 & 1,76 & 42 \\
Río Santiago & 16951 & 8035,28 & 2,11 & 17 \\
Morona & 13492 & 10776,95 & 1,25 & 16 \\
Imaza & 24273 & 4430,84 & 5,48 & 51 \\
Aramango & 10917 & 809,07 & 13,49 & 7 \\
Nieva & 29153 & 4481,63 & 6,50 & 152 \\
Manseriche & 10615 & 3493,77 & 3,04 & 8 \\
\hline
\end{tabular}

Fuente: INEI, PDC de los distritos.

(*) Directorio de Comunidades Nativas Amazónicas del Perú 2016, Instituto del Bien Común.

\footnotetext{
7 El ámbito fronterizo peruano reconocido en el Acuerdo Amplio de 1998 abarca $288063 \mathrm{~km}^{2 \text {, incluyendo los }}$ departamentos de Tumbes y Piura, las provincias de Jaén y San Ignacio (en Cajamarca), las provincias de Bagua, Utcubamba y Condorcanqui (en Amazonas) y las cuencas de la margen izquierda del Marańón-Amazonas hasta el río Napo (en Loreto).

8 Encuentro Presidencial y XI Reunión del Gabinete Binacional - Plan de Acción - Eje de Asuntos Productivos, Comerciales, Inversión y Turismo. Compromiso 15, Trujillo, octubre 2017.
} 


\section{Mapa 1. Zona focalizada PIICA-I}

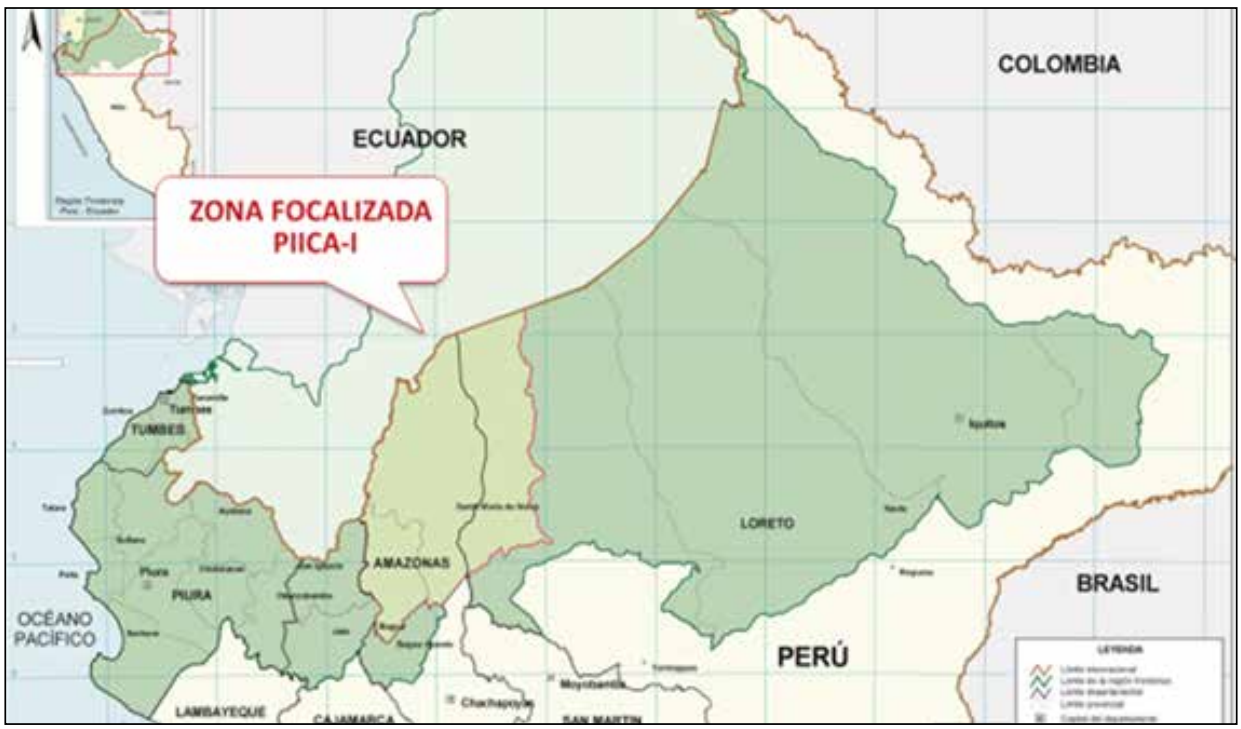

Fuente: Capítulo Perú del Plan Binacional Perú-Ecuador.

\section{Mapa 2. Distritos de la zona focalizada}

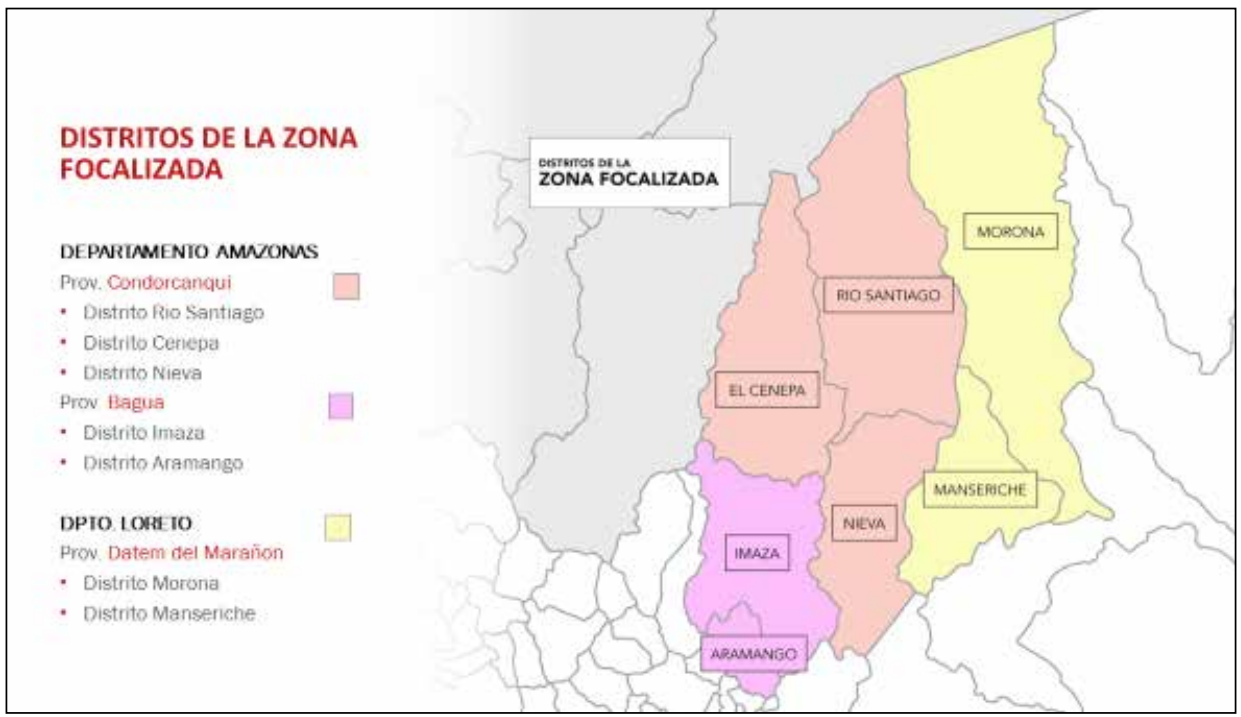

Fuente: Capítulo Perú del Plan Binacional Perú-Ecuador. 
Las cuencas del Cenepa, Santiago y Morona son tributarias de la cuenca del Marañón y están conformadas prioritariamente por bosques húmedos tropicales y heterogéneos, con una fisiografía que se extiende por terrenos agrestes, pendientes, quebradas y zonas anegadas y aluviales. Por su gran biodiversidad, en estas zonas se han creado Áreas Naturales Protegidas (ANP). Albergan un importante número de comunidades nativas siendo el Cenepa y el Santiago, hábitat tradicional de familias awajún y wampis. En la cuenca del Morona existe una mayor diversidad cultural, encontrándose comunidades pertenecientes a los pueblos achuar, awajún, shapra, shawi y wampis. La población, mayoritariamente indígena, se ha organizado en 17 federaciones, 9 en el Morona, 3 en Río Santiago, 1 en el Río Nieva y 4 en El Cenepa.

Las ciudades de Chiriaco (Imaza), Santa María de Nieva (capital de la provincial de Condorcanqui) y Saramiriza (Manseriche), pese a su limitada infraestructura social básica, productiva y de servicios, vienen interactuando bajo intensidades diferenciadas con las áreas rurales de sus propios distritos, así como con las áreas rurales y centros poblados de las cuencas del Cenepa, Santiago, Nieva y Morona, sirviendo como una suerte de corredor de articulación económica local y para la provisión de servicios, incluidos los administrativos e institucionales.

La economía de las cuencas del Santiago, Cenepa y Morona, se basa predominantemente en el desarrollo de actividades de subsistencia: agrícolas, crianza de animales menores, caza y pesca. Las actividades agrícolas tradicionales con potencial de desarrollo en las referidas cuencas están referidas al cultivo de cacao y plátano. Asimismo, la acuicultura, que a partir de una tecnificación primaria se está constituyendo en una actividad con potencialidad para generar ingresos y seguridad alimentaria.

\section{Mapa 3. Modelo territorial de la estrategia}

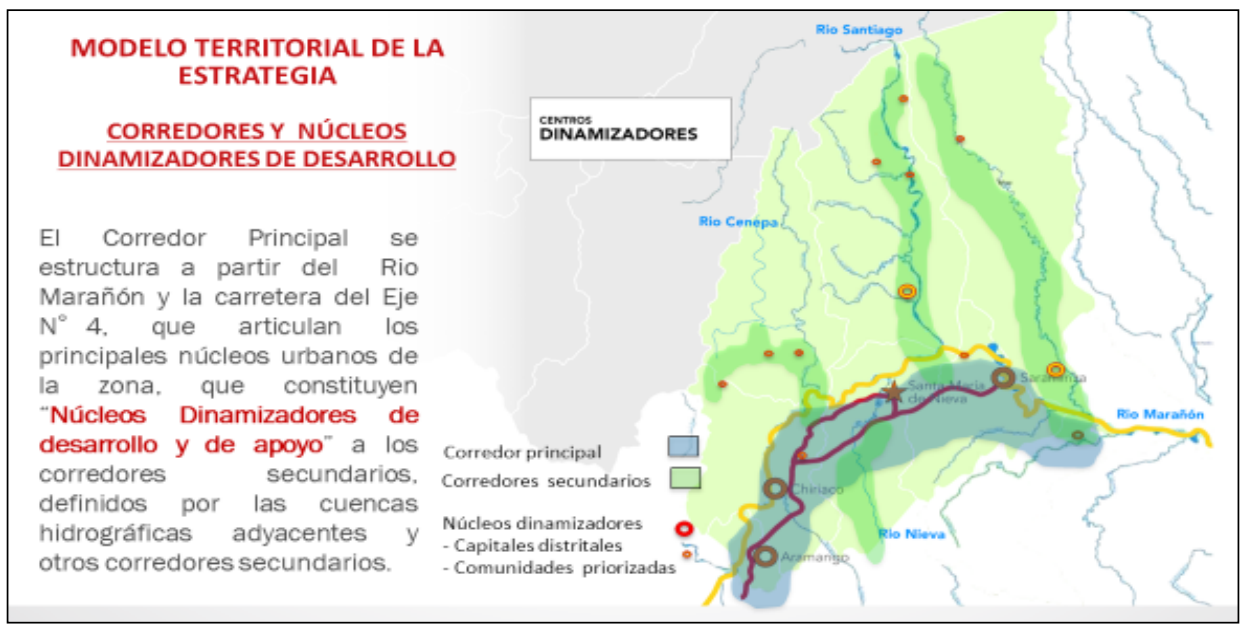

Fuente: Capítulo Perú del Plan Binacional Perú-Ecuador. 


\section{Líneas de acción priorizadas del PIICA-I}

A partir de los lineamientos del Plan Operativo Multianual 2017-2019, el Capítulo Perú sistematizó la información y los requerimientos de desarrollo de los distritos de la zona focalizada y los tradujo en el «Programa de Inversión Inter Cuencas Amazónicas (PIICA-I)» que constituye un modelo estratégico de intervención integrado y sostenible, orientado fundamentalmente a desarrollar capacidades productivas que incrementen los ingresos familiares, contribuyendo a mejorar la calidad de vida y la seguridad alimentaria de los pobladores; a generar cadenas de valor y articulación a mercados para la producción local; a contribuir a mejorar la conectividad local para facilitar el acopio, la transformación primaria y el transporte de productos; y, a promover la asociatividad de los productores de cacao, plátano, piscicultura y productos forestales.

El PIICA-I incluye 29 estudios y proyectos que serán cofinanciados por el Fondo Binacional-Sede Lima, a partir de una inversión de siete millones de dólares a ser ejecutada inicialmente en el período 2018-2019 en un esfuerzo conjunto con instituciones públicas, organizaciones sociales, actores privados, comunidades nativas y población mestiza para elevar la calidad de los servicios públicos y contribuir a cerrar brechas sociales, culturales y económicas.

\section{Desarrollo sostenible en el ámbito focalizado de la frontera}

Conforme a la Ley Marco de Desarrollo e Integración Fronterizos, la promoción del desarrollo sostenible en frontera se orienta a conseguir el equilibrio dinámico entre todos los componentes de la sostenibilidad: en lo económico, socio-cultural, ambiental, de convivencia con el país limítrofe y, en especial, el componente de la sostenibilidad político-institucional o de gobernabilidad.

La formulación del Programa de Inversiones PIICA-I ha brindado especial consideración al impacto y a la sostenibilidad de las actividades y proyectos. Al efecto, los proyectos prevén exigencias relativas a líneas de base y a mecanismos y procedimientos para que los logros alcanzados se radiquen y permanezcan en el ámbito de intervención, incorporándose — cuando corresponda— cómo prácticas socioculturales que se mantengan en el tiempo.

\footnotetext{
9 La formulación del PIICA-I tuvo un amplio carácter participativo, incluyendo consultas a autoridades y funcionarios de los gobiernos locales del ámbito de intervención y ha sido socializado con representantes de la población y de las comunidades beneficiarias, con el Gobierno Regional de Amazonas y con funcionarios de los sectores y entidades representadas en el Consejo Nacional de Desarrollo e Integración Fronteriza (Conadif).
} 
Se trata de un proceso lento, más aún tratándose de una intervención en espacios con significativa presencia de sociedades indígenas que se encuentra en un proceso de transición cultural y económica, presionadas por un lado por las fuerzas del mercado con todos sus efectos positivos y negativos y, por otro, por la resistencia para mantener sus patrones culturales tradicionales.

En la formulación del PIICA-I se analizaron comparativamente aspectos del desarrollo sostenible y sus diversos componentes, relacionándolos con los Objetivos de Desarrollo Sostenible aprobados por las Naciones Unidas ${ }^{10}$ y con la Política General del Gobierno hacia el Bicentenario. La evaluación de sostenibilidad de los proyectos procurará garantizar el mantenimiento no solo de la obra sino de los beneficios a largo plazo. La medición de la sostenibilidad será abordada desde la perspectiva ambiental (equilibrio entre desarrollo y preservación de medio natural), económica (mantenimiento de procesos económicos para el bienestar de las personas) y, social (acceso equitativo a bienes y mejoría de capacidades). Tendrán también relevancia los convenios y acuerdos interinstitucionales que aseguren el mantenimiento y permanencia de las infraestructuras instaladas, la sostenibilidad económica de proyectos de infraestructura productiva, el acceso a mercados y las capacidades mejoradas de los trabajadores locales.

La medición de los impactos no se limitará a buscar indicadores convencionales aplicables a proyectos de inversión, sino también a variables referidas a procesos sociales, económicos y culturales locales, así como a aquellos asociados a la integración y la cooperación transfronteriza, promoviendo espacios de acción conjunta de las autoridades y pobladores y grados de complementariedad entre procesos productivos que puedan formar parte de cadenas productivas o de valor de índole transfronteriza.

\section{Necesidad de activar la intervención integrada de los sectores y programas estatales}

Ante la dificultad de lograr concretar la conformación de un Segundo Grupo Consultivo (2001-2002) que permitiera comprometer nuevos recursos de la cooperación internacional, los gobiernos del Perú y Ecuador decidieron en el año 2003 impulsar un proceso de «Relanzamiento del Plan Binacional», encargando a sendos

\footnotetext{
10 «Los objetivos y metas del desarrollo sostenible tienen en cuenta las diferentes realidades, capacidades y niveles de desarrollo de cada país y respetan sus políticas y prioridades nacionales. Si bien las metas expresan las aspiraciones a nivel mundial, cada gobierno fijará sus propias metas nacionales, guiándose por la ambiciosa aspiración general, pero tomando en consideración las circunstancias del país. Cada gobierno decidirá también la forma de incorporar esas aspiraciones y metas mundiales en los procesos de planificación, las políticas y las estrategias nacionales» (Ítem 55 de la Resolución de NN.UU. que aprueba los 17 objetivos).
} 
comisionados nacionales la tarea de realizar un diagnóstico y formular recomendaciones $^{11}$. El informe del comisionado peruano estuvo «destinado a identificar las limitaciones del Plan Binacional y, al mismo tiempo, plantear medidas que [...] puedan contribuir a convertir en realidades los proyectos que, en caso de concretarse, le permitirán cambiar el rostro a las zonas de los territorios de ambos países comprendidas en los alcances del Plan» (García Sayán, 2003).

El referido informe constató que, después de tres años de inicio del Plan, la población de la región fronteriza seguía esperando — con menos esperanza y mayor exigencia hacia el Estado- que sus expectativas fueran satisfechas. Observó que el Plan Binacional es algo que se encuentra muy «en la piel» de la población, en especial por el desarrollo de los ejes viales y por el respaldo brindado por el Fondo Binacional para la ejecución de una plétora de proyectos medianos y pequeños cofinanciados con municipios y asociaciones locales.

De otra parte, las constataciones más preocupantes del Comisionado peruano se orientaron a señalar que «objetivamente hablando, lo que ha existido es un relativo desinterés del Estado en el Plan Binacional y en la región. Ello se ha expresado de diferentes maneras: El Perú no solo no tuvo en 1998 una propuesta de desarrollo de la región fronteriza en la cual los programas y proyectos estuvieran articulados y orientados al logro del objetivo del Plan Binacional, sino que tampoco tuvo nunca una cartera de proyectos, realista, sustantiva y pertinente a los reales problemas que tiene la región fronteriza» (García Sayán, 2003).

El comisionado destacó que «en los diseños presupuestales de los sectores concernidos nunca se internalizó que el Plan existía y que había que calendarizar la ejecución de los proyectos para que estos no quedasen en papel [...] Lo cierto y evidente es que en el aparato gubernamental nacional el tema del Plan Binacional no existe como referente de estructuración de prioridades o de asignación de recursos» (García Sayán, 2003).

Afirmó también que, en ocasión de la preparación de la cartera de proyectos para un eventual II Grupo Consultivo (2002), «se hizo evidente que los sectores, en mayor o menor medida, según los casos, no expresaron un interés particular en la región fronteriza con Ecuador [...]. El reconocimiento de la realidad de la región fronteriza, por parte de los sectores, es parcial, pertenece a las oficinas regionales y no está articulada a propuestas integrales y pertinentes a las diferentes situaciones problemáticas que se encuentran en la región fronteriza» (García Sayán, 2003).

\footnotetext{
11 Mediante D.S. 033-2003-RE el Gobierno peruano designó al doctor Diego García-Sayán como comisionado nacional peruano.
} 
El informe del Comisionado peruano concluyó formulando 16 recomendaciones, la mayoría de las cuales no fueron implementadas. Sin embargo, a partir del 2004 el Estado peruano respondió positivamente a la necesidad «que se le asigne (al Capítulo Perú del Plan Binacional) una partida presupuestaria que corresponda, al menos en parte, a la que recibe su contraparte ecuatoriana» (García Sayán, 2003).

Esta amplia referencia a los hallazgos del comisionado presidencial peruano resulta pertinente en la medida que retrata en buena medida la situación de relativo interés y de autarquía que han observado la mayoría de los sectores de gobierno hasta el presente. Ha habido inversión pública, sí, pero esta se ha dirigido principalmente a obras de infraestructura física, prescindiendo de enfoques integrados que hubieran podido generar sinergias de desarrollo económico y social y un mayor y más sostenible impacto en la calidad de vida de la población de la region fronteriza. Estas aserciones lamentablemente se comprueban al observar los niveles de las brechas sociales subsistentes, principalmente en las regiones de sierra y selva de la región fronteriza.

Dadas las dimensiones de la pobreza, la extensión y el difícil acceso al territorio, las asimetrías transfronterizas y las particularidades culturales de la Amazonía norte, resulta imprescindible cambiar la estrategia de manera tal de lograr resultados verificables y duraderos en el corto y mediano plazos.

Sobre la base de la experiencia ganada en proyectos recientemente impulsados por el Capítulo Perú en la zona focalizada, la estrategia del PIICA-I se orienta a desarrollar la base productiva y cadenas de valor de cultivos como el plátano y el cacao, así como de emprendimientos piscícolas que ya han demostrado ciertos niveles de éxito como fuentes generadoras de valor. La continuación de esta estrategia permitirá intervenir de manera creativa en el mejoramiento de los sistemas productivos, tanto para generar ingresos para las familias y contribuir a su seguridad alimentaria, como para ampliar sus oportunidades de articulación económica y comercial.

Si bien el PIICA-I constituye una herramienta operativa de desarrollo económico y social, require sin embargo ser ampliamente complementada por una intervención multisectorial integrada y coordinada con el Estado, que priorice la inversión pública orientada a generar impactos reales y que se disocie de la lógica ortodoxa que condiciona la factibilidad de las inversiones en infraestructura a una ratio de utilidad económica.

La nueva estrategia propone que los sectores gubernamentales responsables formulen y ejecuten un programa de conectividad de la red multimodal de transporte en el ámbito focalizado, que tome en cuenta las reales necesidades de articulación vial, fluvial y de comunicaciones y que haga posible el acceso a los mercados y la provision normal de los programas y servicios asistenciales del Estado; un amplio programa de 
dotación de agua segura para las comunidades y centros poblados que acompañe y dé sentido a las campañas de salud; y una implementación extensiva de electrificación rural que abra la posibilidad de iniciar centros de transformación primaria en todo el ámbito de intervención.

El Programa de Inversión Inter Cuencas Amazónicas incluye la realización de un diagnóstico de los servicios básicos en las cuencas del Santiago y del Cenepa que permitirá medir, conforme a la metodología del Ceplan, los niveles de brechas optimizadas a fin de proyectar los niveles de inversión pública requeridos. El diagnóstico permitirá que los sectores del Estado y los gobiernos subnacionales realicen un «barrido» de todo el ámbito de interés, comparando los datos de inversión registrados oficialmente por el Ministerio de Economía y Finanzas y los distintos sectores con el grado actual de operatividad de las instalaciones y servicios existentes ${ }^{12}$. Esta información, debidamente sistematizada hará posible una eficiente y rápida reingeniería de los programas de inversión para la dotación de infraestructura básica funcional, adaptada y contextualizada a la región y a las poblaciones amazónicas.

El PIICA-I incluye dos importantes estudios adicionales. En primer lugar, un diagnóstico sobre la calidad educativa en la provincia de Condorcanqui, que permita al sector Educación indagar cual es la percepción de los actores involucrados (profesores, estudiantes, padres de familia y líderes de las comunidades indígenas) sobre los programas y calidad de la educación que actualmente se imparte en la zona y, asimismo, cuales son sus expectativas con relación a la formación intercultural y técnica que se requiere impartir a los niños y jóvenes indígenas de la zona. El segundo estudio permitirá realizar un diagnóstico sobre las capacidades ya desplegadas y sobre las potencialidades de desarrollo agropecuario y acuícola existentes en la cuenca del Morona, a fin de encaminar las futuras actividades de promoción e inversión productiva en esa extensa región fronteriza.

El impostergable e irremplazable concurso del Estado que promueve el Plan Binacional en la zona focalizada está orientado por enfoques que garanticen que los proyectos que se impulsen no degraden el ambiente, sean técnicamente apropiados, económicamente viables y socialmente aceptables conforme a criterios interculturales.

En términos de sostenibilidad ambiental la gestión de los recursos naturales para mejorar las condiciones de vida de las poblaciones que habitan los ecosistemas frágiles de las cuencas hidrográficas focalizadas no puede realizarse de manera adecuada si no

\footnotetext{
12 «No hay experiencia más frustrante para una comunidad que haber luchado por años para que se instale un sistema de agua en la comunidad y constatar que no está cumpliendo su función; con el efecto agravante que, en el marco de los lineamientos del SNIP, ninguna propuesta para invertir en la misma obra nuevamente podrá ser declarada viable». (Druschke et al., 2012).
} 
se consideran procesos productivos que tomen en cuenta la conservación de la tierra, el agua y los recursos genéticos vegetales y animales existentes, a fin de mantener un equilibrio entre las dimensiones social, económica y ambiental del desarrollo sostenible en un contexto creciente de cambio climático (FAO, 2015).

La propuesta de desarrollo del Plan Binacional se sustenta en un enfoque participativo de los actores involucrados, teniendo presente que los intereses diversos deben verse reflejados de manera consensuada en los instrumentos de planificación. Ello implica que la socialización de los mismos se realice desde el diseño y la formulación de las propuestas hasta su ejecución y evaluación de impactos. Estos procesos suponen una adecuada estrategia comunicacional por parte de las entidades del Estado, centrada en establecer consensos de mediano y largo plazo que faciliten operativizar los proyectos sin problemas.

Según datos del Directorio de Comunidades Nativas del año 2016 (Instituto del Bien Común, 2016), la zona focalizada tiene un total de 293 comunidades nativas reconocidas y tituladas: 168 comunidades awajún, 5 comunidades achuar, 19 wampis y 1 comunidad shapra. En ciertas áreas de mayor desarrollo urbano existen también algunas poblaciones mestizas proveniente de otras partes del país. A fin de facilitar las intervenciones del Estado convendrá que esa realidad social, económica, religiosa y culturalmente diversa sea asumida por un enfoque intercultural que reconozca y valore las diferencias, favorezca las relaciones interculturales, la igualdad entendida como igualdad de derechos y la no discriminación, destacando la diversidad sociocultural frente a la homogeneización. Bajo este enfoque se podrán revertir las dinámicas sociales de exclusión social, discriminación, invisibilización y desigualdad que han venido prevaleciendo sobre las poblaciones nativas del ámbito focalizado.

La situación de la mujer en las sociedades indígenas, específicamente en el ámbito de focalización del PIICA-I, se muestra de manera descarnada en casos de violación de niñas ${ }^{13}$, violencia sexual, suicidios de mujeres por envenenamiento y expansión exponencial del VIH sida en las mujeres y familias indígenas por el contagio adquirido por sus esposos o parejas. Estos hechos demuestran crudamente el bajo nivel de valoración de la mujer indígena y motivan la necesidad que las propuestas de desarrollo del Estado incorporen el enfoque de género, promoviendo transversalmente la igualdad de oportunidades entre mujeres y hombres en las actividades y proyectos que se implementen. A fin de abordar este amplio y complejo reto, el Plan Binacional ha planteado a la Secretaría Ejecutiva del Consejo Nacional de Desarrollo e Integración Fronterizos

\footnotetext{
13 Entre los años 2011-2015 se estima un aproximado de 60 a 80 denuncias anuales ante la UGEL Condorcanqui, por violación de niñas por sus propios profesores (Ministerio de Educación del Perú, 2017)
} 
(Conadif) el establecimiento de una plataforma de articulación intergubernamental llamada a impulsar una acción concertada en favor de una intervención priorizada, armonizada y debidamente integrada en la zona focalizada. Dicha plataforma deberá ser capaz de viabilizar alianzas estratégicas con los gobiernos regionales y gobiernos locales y desarrollar sinergias complementarias con otras entidades públicas y de la sociedad civil para desarrollar instrumentos de planificación, intervención e inversiones y, asimismo, proponer al Gobierno central un mecanismo de financiamiento capaz de atender la magnitud del esfuerzo de inversión requerido.

\section{Conclusiones}

La geografía y los indicadores socioeconómicos del extenso territorio fronterizo norte son marcadamente diferenciados. La pobreza se acentúa en el medio rural y se vuelve más pronunciada a medida que nos aproximamos a la llanura amazónica, hábitat de poblaciones mayoritariamente indígenas que, además, viven un proceso de difícil tránsito de la tradición a la modernidad. Condiciones socioculturales propias y la lejanía de los centros más dinámicos de la economía regional y nacional determinan la falta de oportunidades de trabajo, la imposibilidad de monetizar excedentes y la casi nula formación de capacidades. A esto se suma la precariedad con la que llegan los servicios sociales básicos y los programas asistenciales del Estado, diseñados fundamentalmente para atender a las zonas rurales de la costa y sierra.

En este marco de difíciles condiciones de vida, la débil presencia institucional del Estado constituye un vacío de muy serias consecuencias. La falta de políticas y programas ad-hoc para el desarrollo amazónico denota la invisibilidad de las poblaciones indígenas amazónicas en el contexto nacional. Y el escaso caudal electoral de las poblaciones amazónicas continúa sometiéndolas a la irrelevancia política, incluso en las relaciones con los gobiernos regionales, a partir de los cuales el proceso de descentralización del Estado quiso superar las tradicionales distancias entre el centro y la periferia.

En un contexto de falta de oportunidades de trabajo como el que se verifica en las cuencas de la Amazonía norte, la ausencia del Estado genera un vacío de poder que invita a la anomia social y a la proliferación de actividades ilícitas como la minería ilegal, la tala ilegal y el cultivo y tráfico de drogas.

Es en este ámbito, que forma parte de su mandato, que el Plan Binacional ha encontrado la necesidad de desarrollar un "programa piloto", aplicando nuevos enfoques de intervención focalizada para el desarrollo. El área seleccionada incluye las provincias de Condorcanqui y Datem del Marañón. La primera, ha sido cuna de organizaciones indígenas importantes y ha estado fuertemente relacionada con los sucesos de Bagua (junio de 2009). La segunda, es la última provincia creada en el Perú y concretada por 
presión indígena y promocionada como oferta electoral. Esta última, además, reúne condiciones especiales: conviven en el área al menos 8 étnias distintas, en su mayoría de origen jíbaro; cobija yacimientos petrolíferos (que están o han estado) bajo explotación por importantes empresas petroleras y, conjuntamente con Condorcanqui constituyen la ruta preferida por el Ecuador para desarrollar el Eje Vial $N^{\circ} 5$ que le permita un acceso al eje del Marañón-Amazonas (Druschke et al., 2012).

A esos efectos el Plan Operativo 2017-2019 orienta al Capítulo Perú a promover, articular y dinamizar un proceso programático, fundado en lineamientos estratégicos centrados en intervenciones focalizadas e integradas por corredores de desarrollo, cuencas hidrográficas y núcleos dinamizadores, con la finalidad de ingresar a un proceso de definiciones y planeamiento estratégico que fortalezca la eficacia y sostenibilidad de su intervención, contribuyendo así a elevar la calidad de vida de las poblaciones de la región fronteriza y a superar su situación de atraso con respecto al resto del país.

La promoción del desarrollo debe propiciar el empoderamiento de los grupos objetivo a fin de proporcionarles instrumentos y habilidades productivas (de bienes y servicios) que les permita remontar la fase del asistencialismo. Asimismo, ante la precariedad de las opciones para un retorno a la vida tradicional de caza, pesca y recolección, el paso siguiente en el desarrollo humano del indígena amazónico, tendencialmente, parecería ser el de convertirse en un exitoso agricultor. Así lo han entendido desde hace varios ańos los municipios de los distritos de El Cenepa, Río Santiago y Morona, principales promotores de este cambio, no obstante ser los más desprovistos de recursos y capacidades para el acceso al financiamiento de los programas sectoriales de desarrollo.

Es en ese contexto que el Plan Binacional ha formulado el Programa de Inversión Inter Cuencas Amazónicas (PIICA-I), que busca constituirse en un modelo de gestión integrado y sostenible, en el entendido que constituye un gran reto poner en marcha procesos de desarrollo en ámbitos tan complejos y heterogéneos, con presencia mayoritaria de población indígena, con enormes brechas sociales y con una presencia precaria del Estado, al tiempo de mantener un equilibrio entre las dimensiones social, económica y ambiental del desarrollo sostenible.

A partir del PIICA-I, el Plan Binacional promueve una propuesta estratégica para una intervención integrada, articulada y focalizada del Estado, que priorice programas regionales y sectoriales de inversión por corredores y núcleos dinamizadores de desarrollo económico y social en el ámbito constituido por cinco cuencas insertas en siete distritos amazónicos, a fin de generar un impacto duradero y, eventualmente, orientado a generar condiciones para su replicabilidad futura en otras cuencas de la frontera norte, sin sustituir «[...] las acciones de desarrollo sectoriales ni la de los gobiernos 
regionales y locales en la frontera, sino que las articula, integra y prioriza en función de los intereses nacionales y de los acuerdos internacionales sobre la materia» ${ }^{14}$.

La lógica subyacente es que no hay forma de superar los niveles de pobreza y de cubrir las enormes brechas en la prestación de servicios sociales básicos (educación, salud, saneamiento, electrificación rural y conectividad) que afectan la calidad de vida de las poblaciones amazónicas de la frontera norte basados en meros esquemas asistencialistas, que constituyen la manera tradicional de intervención del sector público en estos espacios.

Para brindar mejor calidad de vida y dar dinamismo a las economías rurales que conforman el inmenso ámbito de las cuencas focalizadas (con una extensión de $37486 \mathrm{~km}^{2}$, similar a la del departamento de Lima) será menester que las entidades públicas y otros actores de la sociedad civil identifiquen modalidades de prestación de servicios que se ajusten a la realidad intercultural en la que operan y que los programas sectoriales de inversión prioricen con criterio político la urgente necesidad de cerrar las brechas fundamentales de agua, electricidad y conectividad.

Finalmente, y como resulta evidente, la gestión del financiamiento requerido incluye, pero ciertamente excede las capacidades del Fondo Binacional y los de la cooperación no reembolsable y hará imperativa la conveniencia política de generar iniciativas presupuestarias ad-hoc.

La estrategia de desarrollo iniciada con el PIICA-I continuará implementándose con el esfuerzo creativo de instituciones públicas sectoriales e intergubernamentales y con la participación de entidades de la sociedad civil y la población organizada, a fin de ajustarse y responder a las características propias de la realidad en que se interviene.

\section{Referencias}

Druschke, M., Alvarado Jesús, J. Pajares, E., Mora, N. y Curo, F. (2012). Diagnóstico de la situación actual de los Pueblos Indígenas amazónicos y Estrategia de Intervención. Lima: Capítulo Perú del Plan Binacional Perú-Ecuador.

FAO. (2015). Construyendo una visión común para la agricultura y alimentación sostenibles - Principios y Enfoques. FAO.

García Sayán, D. (2003). Informe Nacional del Comisionado Peruano. Lima: Capítulo Perú del Plan Binacional Perú-Ecuador.

Giesecke, A., Lafosse S. y Purizaca, J.L. (2003). Informe final de la Consultoría en Cooperación Internacional. Lima: Capítulo Perú del Plan Binacional de Desarrollo de la Región Fronteriza Perú-Ecuador.

14 Literal b, del artículo 46 del Reglamento de la Ley Marco para el Desarrollo e Integración Fronteriza. 
Kisic, D. (2008). Impactos y Retos futuros de los Acuerdos de Paz en el desarrollo económico binacional. En Perú-Ecuador. Evaluación de una década de paz y desarrollo. Lima: IDEA Internacional.

Ministerio de Educación del Perú. (2017). Desenrollando la madeja de la impunidad: rutas de accesos a la justicia en casos de violación sexual contra niñas y adolescentes en zonas rurales y multiculturales de la provincia de Condorcanqui, Amazonas, estudio de una comunidad nativa awajún del Rio Santiago. Lima.

Instituto del Bien Común. (2016). Directorio de Comunidades Nativas Amazónicas del Perú. Lima. Recuperado de http://ibcperu.org/files/Directorio_2016_de_Comunidades_ Nativas.pdf

Novak, F y Namihas, S. (2010). Serie: Politica Exterior Peruana. Perú-Ecuador: Una experiencia exitosa de paz y buena vecindad. Lima: Instituto de Estudios Internacionales (IDEI) de la Pontificia Universidad Católica del Perú y fundación Konrad Adenauer.

Oliveros, L.A. (1998). Breve introducción al conocimiento de la realidad nacional y regionalfronteriza de nuestro vecino del norte. Lima: Ministerio de Relaciones Exteriores del Perú.

Plan Binacional de Desarrollo de la Región Fronteriza Perú-Ecuador. (2017). Listado inversiones levantado por el Capitulo Perú en base a información recogida de los sectores gubernamentales y otras fuentes. Lima

Fecha de recepción: 16 de marzo de 2018 Fecha de aprobación: 15 de junio de 2018 